\title{
Los usos concretos y los significados de la literacidad en una comunidad rural - un caserío mestizo de la Amazonía: organización local, identidad y estatus
}

\author{
Patricia Ames*
}

\begin{abstract}
Resumo
Este estudio indaga, desde una perspectiva etnográfica, sobre los usos y las prácticas sociales alrededor de la literacidad entre la población rural de la Amazonía peruana. Se examinan los diversos ámbitos de la vida cotidiana, como la comunidad, la escuela y el hogar. Al hacerlo, se encuentran evidencias que cuestionan el tradicional estereotipo sobre estas poblaciones como poco dadas al uso de la palabra escrita. En efecto, la literacidad está presente en una diversidad de formas y funciones, asociada fuertemente a la organización local, a la gestión interna de los asuntos comunales y a la relación con las instituciones del Estado. En los hogares, está presente en la organización doméstica, el entretenimiento, la comunicación interpersonal, el acceso a información y el apoyo en la escolaridad de los niños. La escuela, agente central de la alfabetización infantil, margina los múltiples usos de la literacidad en el ámbito comunal y familiar, ofreciendo una versión restringida y descontextualizada de las habilidades letradas. En conjunto, el estudio muestra que los valores y significados asociados a la literacidad están estrechamente relacionados con otros factores políticos, sociales y culturales que permiten comprender los usos y practicas identificados y replantear las formas actuales de su enseñanza formal.
\end{abstract}

Palabras-chaves: Literacidad; escritura; lectura; educación rural; Amazonia

\section{Introducción}

El campo peruano ha sido tradicionalmente considerado como un espacio de escaso uso funcional de la escritura. (GODENZZI; FLORES; RAMÍREZ, 2000, CLASSEN, 1991). Sin embargo, son pocos (y muy recientes) los estudios que se

* É professora do Departamento de Ciencias Sociales - sección antropología, na Pontificia Universidad Católica del Perú e investigadora principal del Instituto de Estudios Peruanos. 
han ocupado de estudiar los usos de la literacidad en el campo como para sustentar empíricamente esta idea. Esta investigación se planteó por ello indagar, desde una perspectiva etnográfica, por los usos y las prácticas sociales alrededor de la literacidad que se vienen dando entre la población rural y en distintos ámbitos de la vida cotidiana, como la comunidad, la escuela y el hogar.

$\mathrm{Al}$ atender los usos concretos y los significados que encierra la literacidad en una comunidad rural - un caserío mestizo a orillas del río Ucayali, a unas cuantas horas de la ciudad de Pucallpa - se encontró un panorama bastante distinto del tradicional estereotipo. La literacidad en el campo aparece presente en una diversidad de formas y funciones, asociada fuertemente a la organización local, a la gestión interna de los asuntos comunales y a la relación con las instituciones del Estado. Asimismo, la encontramos presente al interior de los hogares, tanto para fines de organización doméstica como para el entretenimiento, la comunicación, el acceso a la información y el apoyo a los hijos e hijas en edad escolar. La escuela por su parte, si bien realiza una importante función alfabetizadora entre la población infantil, parece desconocer los múltiples usos de la literacidad en el ámbito comunal y familiar de los niños y niñas y ofrecer más bien una versión bastante decontextualizada y restringida de las habilidades letradas. Estos hallazgos nos obligan a replantear la visión tradicional dominante sobre la literacidad en las zonas rurales. Asimismo, los valores y significados de la literacidad en el campo nos muestran las complejas relaciones que existe entre ésta y otros factores políticos, sociales y culturales, resaltando su carácter eminentemente social. Para desarrollar esta discusión, el artículo presenta los principales hallazgos de la investigación, abordando principalmente el ámbito comunal, pero también los ámbitos del hogar y la escuela. El estudio se organizó en torno al registro y análisis de los eventos letrados (interacciones en las que la escritura o lectura están presentes), las prácticas letradas (la configuración de significados, valores y comportamientos sociales asociados a la escritura) y los textos producto de dichas prácticas y eventos (BARTON 1994, STREET, 2000). 


\section{Los usos de la literacidad en la comunidad rural}

San Antonio es un caserío mestizo ribereño. Sus pobladores se dedican principalmente a la pesca, cuyo producto venden diariamente en el Puerto de Yarinacocha. La pesca se complementa con la agricultura de roza y quema en pequeñas parcelas que producen principalmente maíz, yuca, frijoles y arroz. Una pequeña parte de la producción agrícola se comercializa pero la mayor parte se dedica al autoconsumo. La crianza doméstica de animales de corral, como cerdos y gallinas, también tiene como fin el mercado y el autoconsumo. A pesar de ser un caserío relativamente pequeño (304 habitantes) San Antonio cuenta con centros educativos de inicial, primaria y secundaria, este último para el servicio de comunidades vecinas también. Existe una posta de salud en el caserío para la atención de este y otros poblados vecinos. No hay servicios de energía eléctrica ni agua potable, la cuál se recoge diariamente del río.

Como en otros asentamientos rurales, San Antonio posee una serie de organizaciones locales internas en las que participan prácticamente la totalidad de sus habitantes. La Asamblea Comunal agrupa a todos los adultos del caserío, y elige cada dos años una Junta Directiva Comunal que la representa ante otras instancias. Adicionalmente, cada nivel educativo cuenta con su propia APAFA (Asociación de Padres de Familia), existen dos clubes deportivos, Comité del Vaso de Leche y Club de Madres.

Es justamente en el ámbito de las organizaciones comunitarias donde se pueden observar una serie de prácticas letradas regulares. En efecto, la literacidad juega un papel fundamental en ellas. Toda organización, por ejemplo, mantiene un libro de actas, donde se consigna cada sesión y los acuerdos tomados. El registro escrito en estos casos le da no sólo formalidad a los acuerdos, sino también legitimidad, en tanto estos son materializados en el papel. Como los pobladores suelen decir, "los papeles hablan", indicando que el registro escrito se convierte en algo duradero y en una prueba material de los acuerdos tomados. La firma o huella de todos los participantes de la Asamblea en el acta de cada sesión termina por confirmar aquello que ha sido registrado. La lectura también tiene lugar en las diversas reuniones de estas organizaciones: el acta de la sesión anterior es 
leída al inicio de cada nueva reunión, así como los oficios y cartas dirigidas a la Asamblea. Los reportes de las autoridades y los balances financieros también son leídos y presentados en forma escrita. Las autoridades comunales frecuentemente deben lidiar con una amplia variedad de textos como oficios, cartas, solicitudes, citatorios, comunicados, recibos, memoriales, reportes, padrones, etc., cada uno con funciones y formatos específicos.

Las organizaciones locales se encargan entonces de manejar una serie de documentos escritos que permiten por un lado, establecer una relación con el Estado y sus instituciones y el acceso a los bienes y servicios que éste provee. Por otro lado, los documentos escritos también juegan un rol en la organización de la vida interna de la comunidad. Detengámonos primero en el rol que la literacidad cumple en la relación con el Estado y sus instituciones.

\subsection{La literacidad y la relación con el Estado}

En general, la relación entre la comunidad y el Estado, ya sea para solicitar bienes o servicios básicos, reconocimiento de sus autoridades u organizaciones locales, derechos sobre la tierra u otros recursos, etc., se encuentra siempre mediada por documentos escritos.

El carácter mediador de lo escrito y la importancia de los "papeles" en la relación entre el Estado peruano y sus ciudadanos han sido resaltados en otros estudios (NUGENT 1996, LUND, 2001). Lund (2001), por ejemplo, en su etnografía de los espacios burocráticos en una ciudad andina, enfatiza cómo dichos espacios resultan cruciales para la transformación de valores colectivos y significados subjetivos de la población local, ya que las rutinas del Estado y sus políticas crean sujetos y regulan los significados sociales a través de una determinada práctica textual. Esta reflexión contribuye a analizar no sólo la relación entre el individuo y el Estado, sino también las prácticas letradas comunales que vinculan a un grupo organizado de pobladores con el Estado. Asimismo, permite visibilizar el rol del Estado en promover y modelar el uso de la literacidad en determinadas formas al interior de la comunidad, es decir el uso de ciertos formatos y el carácter burocrático de los textos. Finalmente, como veremos más adelante, la relación de la comunidad 
con la burocracia estatal y sus requerimientos tiene un impacto específico en los valores asociados a la escritura que se generan a través de determinadas prácticas letradas.

En efecto, los pobladores de San Antonio son concientes de la importancia de esta dimensión institucional de la literacidad, que los pone en relación con instancias externas a la comunidad. Por ello, valoran el conocimiento de la lectura y la escritura como necesarios para el ejercicio de cargos de autoridad al interior de sus organizaciones (ver sección 2). En términos más generales, la mediación de lo escrito en la relación con el Estado contribuye a la asociación simbólica de la escritura con el espacio público, en el cuál esta se convierte en una herramienta necesaria para cumplir los requisitos de la propia posición en tanto ciudadano, trabajador, consumidor, autoridad local, etc.

La presencia del Estado como impulsor de determinadas prácticas letradas al nivel de la comunidad (en tanto la relación con este exige el manejo de determinados documentos escritos para la gestión local) también se encuentra expresada a través de las instituciones públicas que operan dentro del caserío mismo, como por ejemplo la posta y la escuela.

Para empezar, ambas instituciones contribuyen a "letrar" el paisaje de la comunidad, tanto con los carteles que indican su presencia al exterior de cada edificio, como con la profusa variedad de material escrito que se encuentra en su interior: afiches, cuadros, tarjetas, folletos, archivos, etc. Más aún, estas instituciones, al brindar sus servicios, generan una serie de eventos letrados en la vida cotidiana de los pobladores rurales. Así, al usar los servicios de salud de la posta, las mujeres embarazadas deben hacer uso y portar una tarjeta de control para el seguimiento de su embarazo. En los primeros dos años de vida de los infantes, las madres deben llevar a cada consulta la cartilla de control de peso y talla de sus hijos, para el seguimiento de su crecimiento y nutrición, así como también el registro de sus vacunas. Desde la implementación del seguro escolar, los niños y niñas en edad escolar deben poseer un carnet para su atención gratuita. Cada cierto tiempo la posta distribuye material impreso entre los hogares, como folletos para el tratamiento y prevención de las enfermedades más comunes. Finalmente, algunos pobladores que son entrenados como promotores de salud, sea por la posta $\mathrm{u}$ otras instituciones (p.e. la iglesia católica o la iglesia adventista), reciben una 
capacitación que involucra la lectura de materiales sobre salud básica y nutrición y deben aprender a manejar cierta documentación (como las cartillas de peso y talla) y escribir reportes sobre los pacientes atendidos.

La escuela asimismo involucra a los pobladores rurales en una serie de eventos letrados: matricular a los niños y niñas en la escuela con su partida de nacimiento, ayudarlos en las tareas, leer las convocatorias para las reuniones de padres de familia, firmar permisos para paseos escolares fuera del caserío, leer las libretas de notas y los comentarios escritos de los profesores sobre el progreso del niño o niña que aparecen en ellas, etc. Para ciertas celebraciones (Navidad, Día del padre, Día de la madre), los niños y las niñas producen tarjetas que llevan a casa y que pueden verse decorando las paredes, así como los diplomas ganados en la escuela. En una ocasión, la semana de los derechos del niño fue celebrada con un pasacalle por el caserío, con los niños y las niñas llevando afiches alusivos a diversos derechos (elaborados por los padres en muchos casos).

A pesar del rol de la escuela en producir algunos eventos letrados en el marco de la comunidad, debe decirse que la mayoría de ellos no son deliberados y en general son escasos. Más bien, la escuela parece considerar su rol como agente alfabetizador mayormente relacionado a la enseñanza directa a los niños y enclaustrado en las paredes de la escuela o las actividades escolares. Como un ejemplo, puede mencionarse que entre la escuela primaria y la secundaria se posee una biblioteca de más de 500 libros. Sin embargo, no se permite ni promueve el uso de estos libros por parte de los pobladores. Se considera que estos libros son sólo para usos de la escuela, aunque muchas veces permanecen sin uso incluso dentro de ella. Ello nos indicaría la visión más bien restringida de la escuela en relación al fomento del aprendizaje de la literacidad, que parece confinado al interior de sus paredes.

Los pobladores rurales también deben establecer una relación, nuevamente mediada por documentos escritos, con instituciones estatales que no se encuentran en la comunidad, sino en la ciudad cercana, como las oficinas de los Ministerios de Agricultura y Pesquería. Los pescadores requieren de un carnet y permiso para realizar sus actividades, y son informados por escrito (frecuentemente a través de la Asamblea) de los períodos de veda para ciertas especies y otras regulaciones sectoriales. Asimismo, los agricultores deben obtener autorización para cultivar 
arroz en los barrizales, que cambian año a año de acuerdo al curso del río. Todas estas gestiones involucran el uso de documentos escritos, el llenado de formularios y la presentación de documentos de identidad en diversas instituciones estatales.

Los documentos de identidad mismos, requeridos para múltiples propósitos (testificar la propia identidad, poseer una propiedad, realizar transacciones bancarias, acceder a ciertos servicios, emplearse en determinados trabajos, votar, etc), deben tramitarse en la ciudad cercana. La habilidad de leer y escribir, así como la familiaridad con los documentos escritos, su organización interna y conexiones lógicas resultan importantes para avanzar en las distintas etapas del proceso de documentar la propia identidad (ver LUND 2001), proceso que se inicia desde el nacimiento mismo. Los pobladores rurales son concientes de la importancia de estos documentos y los guardan en lugares especiales al interior de la casa. Los padres discuten frecuentemente con sus hijos e hijas adolescentes el momento, el lugar y los procedimientos para adquirir la libreta militar y el documento nacional de identidad y enfatizan la importancia de hacerlo para adquirir un estatus legal y evitar "problemas".

Las funciones burocráticas de las prácticas letradas descritas hasta aquí resultan bastante evidentes. Ellas pueden llevarnos a considerar dichas prácticas como una literacidad impuesta, es decir, aquella en la cuál el estilo y el rango de contenido permitidos es establecido por instituciones sociales externas ((IVANIČ, MOSS, 1991) En este sentido, se opondría a una literacidad auto generada, aquella que surge de intereses, necesidades y propósitos propios, y en la cuál uno sería libre de adoptar sus propios contenidos y estilos (ibid).

Aunque esta distinción puede resultar útil para trazar el origen de ciertas practicas letradas en la comunidad y la importancia de ciertos agentes externos para reforzarlas (como el Estado), no siempre es fácil trazar una clara divisoria entre ambos tipos de literacidad. En San Antonio, a pesar de que gran parte de la escritura y lectura realizada por las organizaciones locales y los individuos se puede considerar como impuesta debido a los requerimientos establecidos externamente por la burocracia estatal, ambas pueden servir también para usos y propósitos locales, como veremos en la siguiente sección. La frontera entre literacidad impuesta y auto generada aparece entonces más compleja y difusa. 


\subsection{La literacidad y la organización interna}

Como se indicaba al principio de esta sección, la literacidad en el marco de las organizaciones locales cumple un rol importante en la relación que estas establecen con el Estado y sus diversas instituciones. Al mismo tiempo, sin embargo, la literacidad también es utilizada en la organización interna de la comunidad. En efecto, las organizaciones locales deben resolver una serie de necesidades de organización interna y esto se realiza frecuentemente haciendo uso de documentos escritos.

Empecemos con un ejemplo concreto: la organización de la festividad anual por el aniversario del pueblo. Esta festividad es de carácter eminentemente local y es organizada por los pobladores. Se planea, ejecuta y evalúa a través de la Asamblea Comunal. Cada miembro de la Asamblea asume deberes en algún comité y brinda contribuciones para la realización del festival (p.e. dinero, gallinas, bebidas alcohólicas). La Asamblea realiza un seguimiento a la participación de cada miembro a través de un registro escrito en el que el tesorero marca las contribuciones hechas por cada persona. Los pocos deudores son multados y deben pagar a la Asamblea las contribuciones que no se realizaron a tiempo.

Otros documentos escritos también se producen en el marco de la festividad. Se hicieron por ejemplo oficios solicitando la colaboración y participación a los encargados de diversas instituciones (los directores de los centros educativos, la enfermera de la posta, el sacerdote) o de servicios locales (dueños de los botes de transporte público). También se enviaron cartas de invitación a caseríos vecinos y sus clubes deportivos para que participen del campeonato deportivo y la fiesta. Finalmente se organizó por escrito el programa de las celebraciones, que duraban una semana, a fin de leerlo a la Asamblea. El programa se copió en papelotes y se colocó en diversos puntos de la calle principal.

Estos eventos letrados fueron auto generadas por los pobladores y sus representantes sin que medie ningún requerimiento externo o impuesto, sino como parte de su propia necesidad de organizar, dar seguimiento y comunicar sus actividades. El uso de documentos escritos implicaba al mismo tiempo una mayor formalidad en la organización de la festividad y ello parecía resaltar la importancia de 
la misma. Aunque se usaron textos de tipo similar a los que se emplean en relación con instituciones externas (oficios, cartas), el uso de los mismos servía a un propósito diferente (la organización de un evento interno) y respondía por tanto a necesidades propias de los pobladores. Más que una simple transferencia, los pobladores recrearon los usos de los documentos escritos desde una demanda externa hacia una necesidad interna.

Este tipo de eventos letrados auto generados ocurren de modo más regular en la comunidad y no sólo para eventos especiales. Un conjunto de normas que regulan la vida en la comunidad por ejemplo, se consagran por escrito en un reglamento, así como también las regulaciones para el comercio informal que tiene lugar en las ocasiones especiales como campeonatos y fiestas. Para la organización de las faenas, que tienen como propósito resolver necesidades de la colectividad (limpiar y deshierbar los senderos que conducen al puerto u otros caseríos, el cementerio o la cancha de fútbol; pintar o reparar el local comunal, la iglesia o la escuela, etc.), se utilizan listas con los nombres de cada miembro de la comunidad y se marca su asistencia y cumplimiento en la jornada. Los ausentes reciben una multa que deben pagar a la Asamblea. La literacidad es así usada para organizar y controlar la fuerza laboral comunal.

Esta apropiación de la escritura para fines de la organización interna de la comunidad y la contabilidad de la fuerza laboral comunal parece bastante extendida en las zonas rurales. Los trabajos de Salomon por ejemplo en diversos lugares de los Andes peruanos (como las provincias de Huarochirí en Lima y Azángaro en Puno) han mostrado el uso de la escritura para el registro de la participación en faenas, la contabilidad interna, la historización de las obras comunales, la cartografía y mensuración de las tierras y el archivo de documentos legales (SALOMON, 2000;1997).

Así, si bien el uso que los pobladores rurales hacen de la literacidad puede recurrir en determinados momentos a formatos generados externamente, esto se hace desde un uso particular y con propósitos y necesidades propios, demostrando un proceso de apropiación de la escritura para los fines internos de la comunidad, lo cuál también se puede apreciar en el ámbito del hogar. 


\subsection{La literacidad en el hogar}

La literacidad es usada en el ámbito más íntimo del hogar de distintas maneras y respondiendo a necesidades de los propios pobladores rurales. La encontramos por ejemplo cumpliendo un rol en la organización doméstica, a través del uso de listas de compras para quienes viajan a la ciudad o pequeños recados para familiares que habitan en ella. La comunicación con los parientes fuera de la comunidad se realiza también por escrito, a través de mensajes o cartas (aunque crecientemente se implanta el uso del teléfono para comunicarse con los que habitan en las ciudades alejadas).

La literacidad también cumple un papel en la expresión de afecto, y encontramos el uso más bien secreto de cartas de amor entre adolescentes y entre adultos. Estas cartas expresan, en un lenguaje formalizado, pero bastante explícito, los sentimientos de quienes las escriben y constituirían un canal alternativo si la expresión de dichos sentimientos en la comunicación verbal se considera impropia (la escritura con fines de expresión de los propios sentimientos y experiencias también se reporta en el artículo de De la Piedra en este volumen).

La lectura aparece también en el hogar, asociada al consumo de medios de comunicación. Aunque no hay una distribución regular de periódicos y revistas en las zonas rurales, estos se adquieren en los viajes a las ciudades y una vez en el caserío, son compartidos con otros miembros de la familia. En la lectura de periódicos se enfatiza el deseo de acceder a información de lo que sucede en otros lugares, pero también el deseo de recreación, en particular asociada a las páginas deportivas. Dada la irregularidad del acceso a periódicos, la radio continúa siendo la principal fuente de noticias de actualidad - prácticas similares se reportan en el estudio de las zonas rurales de Yauyos. (ver ANDERSON, 2001). La televisión introduce también mensajes escritos y está presente en varios de los hogares del caserío (24 de 50).

La lectura no sé limita sólo a estos materiales. Existen libros en casi todos los hogares en el caserío (45 de 50), predominantemente libros escolares y religiosos (82\%) y en menor proporción libros técnicos $(14 \%)$ y de ficción $(4 \%)^{1}$. Los adultos

1 Porcentaje del tipo de libros reportados sobre el número de hogares. Fuente: Censo comunal. 
reportan la lectura de cuentos infantiles y de los libros de texto de los niños, no sólo para ayudarles en las tareas sino también con fines recreativos. Asimismo, se reporta la lectura de la Biblia, con fines más bien de formación moral y religiosa, y de cancioneros, con fines recreativos (para cantar).

Finalmente, los adultos y jóvenes se involucran en el uso de la escritura y la lectura al proveer de apoyo a los escolares en sus tareas - ver también el trabajo de Uccelli (1999) en una comunidad cusqueña. En este caso, se encuentra un patrón más bien escolarizado en las interacciones, en el sentido en que intenta reproducir los patrones de relación profesor alumno y las estrategias tradicionales de la enseñanza escolar (copiados, dictados, sanción de errores ortográficos, gramaticales y de pronunciación, etc.), que no se encuentran en eventos letrados más espontáneos ni en las estrategias de aprendizaje informal al interior de la familia.

A este panorama de los usos de la literacidad en el campo podríamos agregar su uso en eventos religiosos, como la lectura de la Biblia y la reflexión sobre sus contenidos, que varía en distintas denominaciones religiosas - ver, por exemplo el trabajo de Zavala (2002) sobre el uso de lo escrito en una iglesia adventista rural. También podríamos extender la mirada sobre el uso mixto de la literacidad y el cálculo en las transacciones comerciales que realizan constantemente los pobladores rurales para la venta de sus productos y trabajo, la compra de bienes de consumo o los préstamos de dinero. Asimismo, los carteles indicando la venta de productos y los impresos de productos comerciales al interior de las pequeñas tiendas contribuyen al paisaje letrado de la comunidad. De otro lado, aunque no se observó en el caso estudiado debido a la ausencia de este tipo de instituciones en el caserío, el trabajo de las ONGs de desarrollo y de los programas estatales involucra frecuentemente a los pobladores rurales en el uso de materiales escritos, como por ejemplo en los talleres de capacitación o charlas informativas (ver ANDERSON, 2001).

Con todo ello, podemos llegar a la conclusión de que la literacidad en el campo adquiere muchos más usos funcionales de los normalmente reconocidos, y se usa para una extensa variedad de propósitos y funciones. La imagen que emerge de este recuento, difícilmente podría pues considerar dichas zonas como espacios iletrados: la literacidad está presente en la vida cotidiana de los pobladores rurales, 
desde su relación con el Estado, el acceso a servicios públicos y la organización interna de la comunidad, hasta para fines recreativos, comunicativos, informativos y de organización doméstica al interior del hogar.

Sin embargo, esta extendida presencia de la literacidad en el campo parecería invisible para la escuela. En ella, los profesores frecuentemente se quejan de sus dificultades para lograr que los niños aprendan a leer y escribir debido a la "ignorancia" de sus padres, su bajo nivel de instrucción y su falta de apoyo. Los profesores establecen su punto de comparación en una imagen "ideal" del padre de familia que tiene como modelo a un sujeto masculino, urbano, profesional, de clase media. En la medida en que los pobladores rurales difieren de este modelo y no muestran las prácticas letradas correspondientes al mismo, los profesores no toman en cuenta las prácticas concretas que tienen lugar a su alrededor ni las incorporan en las estrategias de aprendizaje escolar, como veremos a continuación.

\subsection{La literacidad en la escuela}

La escuela, lejos de utilizar el repertorio comunicativo oral y escrito que los niños y niñas pueden observar a su alrededor (y que se incluye en el mandato de la diversificación curricular), ofrece un rango bastante restringido de prácticas letradas. Los métodos más usados recurren al copiado y al dictado, los libros son escasamente usados, no se promueve su uso para la búsqueda de información, ni para la reflexión sobre los contenidos que presentan, como no sea su memorización. La producción escrita es raramente promovida como medio de expresión, y más bien se insiste en el copiado o la reproducción de formatos de texto (y quizás en este sentido aporta de alguna manera al uso de formatos que se requerirán cuando adultos, ya sea como parte del ejercicio de cargos o para resolver los requerimientos de la burocracia estatal).

En general la literacidad en la escuela se presenta de modo descontextualizado (es decir por fuera del contexto de uso cotidiano) y tiene sentido dentro del ámbito escolar (para hacer las tareas, ejercicios, resolver los exámenes, pasar de grado, etc.), pero difícilmente más allá del mismo. No es que no se considere útil para la vida futura de los niños y niñas, sino que no se fomenta su uso más allá de los 
propósitos escolares. Los niños y las niñas por tanto no son estimulados a explorar los usos de la literacidad en relación a sus propias necesidades de información, recreación o comunicación presentes y más allá de las obligaciones escolares, ni para el conocimiento de su entorno natural o social.

Los pobladores rurales demuestran una activa apropiación de la literacidad para determinados usos y propósitos al interior de la comunidad, pero la escuela parece fallar en reconocerlos y en ofrecer una gama más amplia de habilidades letradas, así como nuevas formas de apropiación y uso que resulten más relevantes a las necesidades concretas de los pobladores rurales. Asimismo, la escuela parece desconocer el carácter eminentemente social de la literacidad, al encerrarla en el marco institucional en que se inscribe. Sin embargo, la literacidad lleva aparejados significados y valores sociales y culturales, que exploramos a continuación.

\section{La importancia de la escritura: organización local, identidad y estatus}

La literacidad no sólo es usada en los diversos ámbito de la vida cotidiana, sino que también conlleva determinados significados para sus usuarios. Podemos identificar dos niveles en relación a la importancia de la literacidad tal como la consideran los pobladores rurales. El primero tiene que ver con la participación a nivel local y el segundo con aspectos más generales en relación a la sociedad en general.

En relación al primer punto, los pobladores de San Antonio enfatizan la importancia de la literacidad para que sus hijos puedan ser en el futuro autoridades en el caserío, y así "servir" a su pueblo.

yo le digo a mis hijos que vean, ¿no? que uno no solamente va a vivir en una comunidad por gusto, hay que servir verdaderamente, con ese amor a nuestro pueblo con lo que se pueda, realmente recibir el cargo y hacer ver que uno verdaderamente tienes la capacidad para que asumas tal cargo ¿no? (Sr. Wilson)

La literacidad pues aparece como una herramienta necesaria a fin de ser una persona útil a la comunidad. Incluso analizando su propia experiencia, los 
pobladores reconocen la importancia que el dominio de la lectura y la escritura ha tenido para poder ejercer los cargos de autoridad que han ocupado. La literacidad resulta entonces una herramienta que posibilita la participación en las organizaciones locales, pero también es una herramienta a ser compartida, para servir a los demás, en este sentido, compartiendo el conocimiento de uno. La literacidad pues involucra tanto significados individuales como colectivos.

Ello es más claro aún en el caso de aquellas personas que ocupan cargos de autoridad pero no saben leer y escribir. Si bien la mayoría reconoce que esto es difícil, la presidenta del Club de Madres se encuentra en dicha situación, pero no parece considerarlo un obstáculo insalvable. Ella enfatiza más bien que para enfrentar las tareas escritas que su cargo supone, recurre a la organización, a las otras miembros de la junta directiva, a la secretaria o incluso a sus parientes. La organización la ha elegido para ocupar este cargo, y ello demuestra que otros factores, como la confianza hacia su persona y las redes que pueden apoyarla en estas tareas, pueden resultar más relevantes que el conocimiento de la lectoescritura. En este caso entonces, se estaría recurriendo a intermediarios de la escritura para cubrir las necesidades de aquellos miembros de la comunidad que no saben leer y escribir, sin que eso los descalifique para ocupar algunos puestos de representación. Esta situación (el uso de intermediarios en actividades letradas) ha sido observada en comunidades andinas (LUND, 1997; ZAVALA, 2002; DE LA PIEDRA, 2003) y ha mostrado cómo la escritura puede convertirse en un bien colectivo y no exclusivamente individual.

En el caso de San Antonio, donde la mayor parte de su población sabe leer y escribir ${ }^{2}$, la tendencia es hacia la adquisición individual de estas habilidades, aunque su carácter de bien colectivo no ha desaparecido totalmente. Además de posibilitar la participación pública a nivel local, los pobladores indican la importancia de saber leer y escribir para ayudar a los hijos en su educación escolar. Esto se refiere particularmente para las mujeres, sugiriendo un patrón genérico en relación a la literacidad, donde las mujeres estarían a cargo de sus usos domésticos (incluida la enseñanza de los niños) y los varones de sus usos más públicos. Esto se infiere del hecho que la mayoría de cargos de autoridad recae sobre los varones (a excepción de las organizaciones propiamente femeninas como el Club de

2 Sólo el 4\% de la población mayor de 15 años no asistió nunca a la escuela. Fuente: Censo comunal. 
Madres y el Comité del Vaso de Leche) aún cuando el promedio de educación de las mujeres es bastante similar (6.- 8 años de escolaridad) al de los varones (7 - 4 años).

En un segundo nivel la escritura reviste una importancia más general: Se considera que es necesaria para "ser alguien", "para mejorar de lo que uno es", "para defenderse". No saber leer y escribir aparece asociado a la posibilidad de ser engañado, a la imposibilidad de defenderse del abuso y permanecer en la pobreza y la subordinación. La literacidad entonces es central para ganar un cierto estatus, para ser alguien en la vida. Los referentes más concretos de estas afirmaciones un tanto generales están asociados a la posibilidad de lograr mayores niveles educativos, llegar a ser profesional, conseguir trabajo asalariado en la ciudad, establecer transacciones comerciales sin miedo a ser engañado y en general con la posibilidad de movilidad social.

La literacidad vista como una herramienta de progreso personal y material en una sociedad marcada por profundas desigualdades ha aparecido recurrentemente en diversos estudios en la zona rural andina y amazónica (ANSIÓN, 1989; MONTOYA, 1990; DEGREGORI, 1991; AMES, 2002). Tiene por tanto una extendida presencia entre los pobladores rurales y está marcada por una historia de exclusión que éstos han vivido en relación al acceso a la escuela. Al mismo tiempo esta visión internaliza un discurso hegemónico sobre el analfabetismo como causa directa de la pobreza de los pobladores rurales (ZAVALA 2002), cuando más bien éste aparece frecuentemente como una consecuencia de la pobreza y la exclusión de estos sectores (STREET, 1995).

Finalmente, la literacidad también aparece de modo central en la búsqueda de reconocimiento social, en la necesidad de ganar un estatus y afirmar una identidad que permita negociar la propia posición social frente a otros. En este sentido, el acceso a la escritura, si bien ha ido de la mano con un deseo de democratización en la población rural, también se ha convertido en, o se ha mantenido como, un elemento de diferenciación jerárquica. En el caso de la comunidad que nos ocupa, es posible identificar cómo la literacidad opera para posicionar a un individuo en mejores términos en su relación con otros individuos o grupos. Al hacerlo, la literacidad se convierte en una herramienta no sólo para volverse "igual", sino también para diferenciarse, para ponerse a uno mismo en una mejor posición social que otro. 
Para entender cómo la literacidad juega un rol en este proceso, es necesario remarcar la diferenciación social en la región y el país y cómo los sujetos establecen su propia posición social en este contexto. El trabajo de Gow (1991) en la región del Alto Ucayali/Bajo Urubamba nos ofrece una caracterización del sistema social en la Amazonía que guarda muchas similitudes con el observado en el Bajo Ucayali. Gow señala que diferentes "clases de gente" se identifican a través del simbolismo del espacio y la civilización, a través de categorías étnicas y situaciones materiales.

Para empezar, Gow señala que se trazan diferencias entre distintos tipos de espacios a lo largo de un continuum entre dos polos extremos: el monte y la ciudad. El monte es visto como hostil para los humanos y la ciudad como el lugar de mayor interferencia humana. Otros tipos de espacios se catalogan en términos de su cercanía a un polo o al otro. La gente es clasificada de acuerdo al lugar en el que vive, pero también al tipo de contacto que mantienen con el mundo de fuera y la "civilización". Así, la gente "que vive en el monte" tiene escaso contacto con la civilización, en contraste con la gente "que está siendo civilizada", quienes mantienen un contacto más intenso con la sociedad nacional y consumen mercancías que no se producen en el bosque. Sobre esta clasificación hay también diferencias étnicas que van desde la gente nativa (indígena) hasta la gente blanca. Una vez más se trata de un continuum de clases de gente, que está estrechamente conectado con el continuum espacial que va del centro del monte hacia fuera. No hay posiciones e identidades sociales fijas ya que estas se definen de modo relacional, y la gente posiciona a otros y a sí mismos al interactuar en situaciones particulares. A estas diferencias subyacen también situaciones materiales concretas, como la pobreza y la riqueza, donde la gente rica es situada más cerca del polo civilizado, ya sea por su conocimiento, su capacidad de adquirir mercancías producidas fuera del bosque y su falta de necesidad de trabajar por comida. En contraste, la gente pobre necesita trabajar en las chacras para alimentarse y tienen acceso limitado al dinero para adquirir mercancías externas.

Estas variadas formas de establecer diferencias entre las personas muestra múltiples jerarquías en la región y cómo estas son establecidas principalmente en términos relacionales. Así, los pobladores mestizos de San Antonio, quienes viven más cerca de la ciudad y a la orilla del río y tienen orígenes étnicos mixtos, 
se encuentran a sí mismos más cerca de la vida "civilizada" que sus vecinos de otras comunidades. ${ }^{3}$ Una mujer que explicaba su disgusto por el pretendiente de su hija mostraba el uso de tales categorías en su discurso. Ella argumentaba que el muchacho vivía lejos del río, que ella no había criado a su hija para que viva "en medio del monte" y que le preocupaba el tipo de vida que él le podía ofrecer. Agregaba luego que el muchacho tenía un apellido de paisano (nativo) -lo que indicaba un origen indígena- y que por lo tanto no podía presentarlo a la familia de su esposo. Como el muchacho siguiera insistiendo, fue confrontado por la mujer, su esposo y su cuñado, usando estos mismos argumentos.

Pero así como los pobladores de San Antonio pueden verse a sí mismos en una mejor posición social que otros, ellos también pueden ser situados por otros como gente "del monte" o "de la chacra" y pueden por lo tanto sentirse posicionados en un status social inferior:

(hablando sobre un curso de capacitación en Pucallpa) a veces me quería cohibir, sentirme menos que ellas, porque eran pues, este, gente de la ciudad, decían pues de la chacra, ellos se creían, nos hacían oír que ellos saben todo, esto es fácil, que esto es así, yo le hago, y como yo era de la chacra, yo les miraba, me reía nomás de ellas, y cuando llegaba mi turno yo salía, a veces quería tener vergüenza, pero como digo, yo también soy un ser humano, pero debo hacer, digo, no debo quedar, no soy más ni menos que ellos, no porque ellos son de la ciudad me van a querer bajar (Sra. Luisa).

En el complejo proceso de establecer la propia posición social en las jerarquías sociales de la región, la literacidad parece tener un papel que jugar. Luisa por ejemplo, al enfrentar el temor de sentirse menos, intenta mejorar su participación en el curso. A lo largo de su entrevista, quedó claro que su escolaridad y sus habilidades de lecto-escritura le daban mayor confianza en sí misma, le permitían realizar las tareas indicadas y superar sus sentimientos de vergüenza. En efecto, algunos estudios que se han ocupado de la importancia de la adquisición de la escritura o el acceso a la escolaridad para las mujeres

3 La importancia del simbolismo del espacio y el tipo de asentamiento también se expresa en la insistencia de los pobladores de San Antonio respecto a las mayores proporciones que tenía el caserío unos años atrás, antes que una inundación obligara al traslado y reducción de la población. 
han mostrado que más que cambiar radicalmente su posición y estatus social en la sociedad, esto les ha ayudado a construir una imagen más positiva sobre sí mismas a partir de la cuál tomar decisiones para mejorar sus vidas (ROBINSONPANT; TOVAR, 1996).

El mismo proceso puede observarse en otros grupos subordinados en la región, esta vez en la relación entre mestizos e indígenas. Algunos jóvenes shipibos de comunidades vecinas asisten a la secundaria en San Antonio, y sus familias recurren a la posta de salud del caserío. Los pobladores mestizos de San Antonio hacen un continuo esfuerzo por diferenciarse de la gente indígena, debido al menor prestigio social que se les concede de acuerdo a los criterios ya explicados. Así, los pobladores mestizos no consideran a los indígenas como "gente como nosotros"; ellos son "otra clase de gente". La literacidad y la escolaridad aparecen como herramientas para reforzar esta diferenciación, y esto es percibido por los jóvenes shipibos, quienes buscan acceder a la escolaridad, el castellano y la literacidad para "no sentirse menos", en palabras de Milder (estudiante shipibo del colegio), menos que los mestizos, menos que los urbanos, menos que otros que puedan invocar una estatus social superior.

Estos ejemplos nos muestran como la literacidad se convierte en una herramienta para posicionarse uno mismo en relación a otros individuos o grupos. En el caso de Luisa, su conocimiento de la lecto-escritura aparecía entre su repertorio de herramientas para hacer frente a la discriminación y demostrar sus capacidades, fijando una posición en términos más equitativos ("ni más ni menos") con individuos o grupos que se consideran por encima de la propia posición social. En el caso de la relación entre mestizos e indígenas, la literacidad por el contrario puede usarse para diferenciarse de individuos o grupos que se consideran por debajo de la propia posición social y así mantener la diferenciación jerárquica.

La literacidad entonces cumple un rol en la dinámica de las relaciones sociales entre individuos y grupos en la región, en tanto tiene un valor para el proceso de negociación de la propia posición social. Más aún, si la consideramos en el continuum monte-civilización, la literacidad aparece asociada a la retórica de la civilización y el progreso, al conocimiento de afuera, es decir, al polo más prestigioso del continuum, como lo demuestra la insistente asociación de la misma con "ser algo en la vida". La retórica de la civilización y el progreso que 
subyace al acceso y difusión de la educación y la alfabetización, señalada por varios estudios (Montoya, 1990, Zavala 2002) aparece también aquí, y al mismo tiempo se integra en relaciones sociales y dinámicas de poder propias de la región.

La literacidad aparece entonces no sólo como un conocimiento o habilidad técnica, sino que está fuertemente ligada a las estructuras de poder y la diferenciación social en un contexto social diverso, conformado por grupos de diferentes orígenes y estatus que negocian constantemente su propia posición, más que permanecer en posiciones claramente delimitadas.

Al mismo tiempo, ya se ha señalado cómo la literacidad sirve para relacionarse con el contexto nacional más amplio, con instituciones públicas y con el Estado peruano mismo, cuyas demandas burocráticas involucran frecuentemente su uso. Ello no quita que la literacidad también es apropiada por los pobladores rurales, que reproducen pero también recrean la palabra escrita para sus propios usos.

En resumen entonces, la literacidad aparece como una herramienta para ganar un cierto estatus y definir una identidad que permitan tanto una relación con el Estado (manejando documentación para acceder a servicios, derechos y ciudadanía), con el mercado (realizando transacciones comerciales, obteniendo empleos) y con otros grupos sociales a nivel regional y nacional (al establecer una posición en la estratificada estructura social peruana).

\section{Conclusiones}

El apretado pero nutrido panorama de los usos y significados de la literacidad en el campo presentado hasta aquí nos permite rebatir algunas imágenes estereotipadas sobre el carácter "iletrado" de las zonas rurales. Para empezar, ha quedado ya bastante claro que la literacidad juega un rol en la vida cotidiana de los pobladores rurales, sirve a una serie de propósitos ya sean internos o externos y constituye parte de la experiencia vital incluso de aquellos que no saben leer y escribir pero que se enfrentan a los documentos escritos recurriendo a intermediarios. En todo caso, lo que parece suceder es que muchos usos locales de la literacidad en el campo permanecen invisibles para otros y por ello no cuentan en la representación que se hace de esta población, ni en las estrategias educativas que se plantean en la escuela. 
Otro aspecto esencial resaltado en este estudio y señalado por varios otros autores (STREET, 1984; 1993; BARTON, 1994; BARTON; HAMILTON, 1998; BLOCH, 1993; HEATH, 1983) es el carácter eminentemente social de la literacidad y como ella está inserta e imbricada en un determinado contexto social y cultural. Así, encontramos por un lado que los usos y significados que conlleva la palabra escrita para los pobladores rurales de San Antonio aparecen fuertemente influenciados por la relación que los pone en contacto con el Estado, tanto a nivel colectivo como individual. Desde el manejo de documentos escritos para acceder colectivamente a servicios públicos o programas sociales, hasta la adquisición de un estatus legal de ciudadano a través de los documentos de identidad, la literacidad aparece como un requisito central de la burocracia estatal y de la relación que el Estado establece con sus ciudadanos. Esta relación imprime su huella no sólo en los eventos letrados, en los textos producidos, sino también en las prácticas sociales y en el complejo de valores que se construyen en torno a la literacidad. Por ello encontramos que la literacidad tiene mayor presencia en los ámbitos de participación y negociación pública, como son las organizaciones locales.

Por otro lado, a pesar de la imposición de ciertos tipos de literacidad (p.e. burocrática) desde instituciones externas a la comunidad, encontramos también la apropiación interna de la misma, para propósitos y fines autogenerados que van desde la organización interna hasta la expresión de afecto. Los pobladores rurales no son pasivos en su uso de lo letrado y por el contrario recrean y se apropian de sus usos no sólo para resolver las necesidades prácticas de su vida cotidiana, sino también para definir identidades, proyectos y una posición social en el complejo panorama de las relaciones sociales de su región y su sociedad. Una sociedad en la cuál la literacidad no tiene un valor neutral, sino que está ligada a procesos sociales que la convierten en una herramienta para la democratización y la participación, pero también para la diferenciación jerárquica. 


\title{
Os usos concretos e os significados do letramento em uma comunidade rural - uma aldeia mestiça da Amazônia: organização local, identidade e status
}

\begin{abstract}
Resumo
Este estudo indaga, sob uma perspectiva etnográfica, os usos e as práticas sociais relativas ao letramento na zona rural da Amazônia peruana. Examinaram-se os diversos âmbitos da vida cotidiana, como a comunidade, a escola e o lar. Os resultados apontam indícios que questionam o estereótipo tradicional destas populações relativo ao pouco uso da palavra escrita. $\mathrm{Na}$ verdade, o letramento está presente em uma diversidade de formas e funções, associada fortemente à organização local, à gestão interna dos assuntos comunitários e à relação com as instituições do Estado. Nos lares, está presente na organização doméstica, no entretenimento, na comunicação interpessoal, no acesso à informação e no apoio à escolarização das crianças. A escola, agente central da alfabetização infantil, marginaliza os múltiplos usos do letramento no âmbito comunitário e familiar, oferecendo uma versão restrita e descontextualizada das habilidades letradas. Concluindo, o estudo mostra que os valores e significados associados ao letramento estão estreitamente relacionados com outros fatores políticos, sociais e culturais que permitem compreender os usos e práticas identificados e repensar as formas atuais do ensino formal.

Palavras-chave: Letramento. Escritura. Leitura. Educação rural. Amazônia.
\end{abstract}

\section{Les emplois concrets et les significations de la littéracie dans une communauté rurale - un village métis en Amazonie: organisation locale, identité et status}

\section{Résumé}

Cette étude s'enquiert, à partir d'une perspective etnographique, des usages et des pratiques sociales autour de la littéracie parmis la population rurale de l'Amazonie peruvienne. Les différents aspects de la vie quotidienne sont analysés, comme, par exemple, la communauté, l'ecole et le foyer. En ce faisant, on trouve des évidences qui questionnent le stéréotype traditionnel concernant ces populations en tant que peu utilisatrices du mot écrit. En effet, la littéracie est présente dans une diversité de formes et de fonctions, fortement associée à l'organisation locale, à la gestion interne des affaires 
communale set aux rapports avec l'État. Dans l'organisation domestique du foyer, il y a le divertissement, la communication interpersonnelle,, l'accès à l'information et le support à la scolarité de enfants. L'école, agent central de l'alphabétisation des enfants, côtoie les multiples usages de la littéracie dans les domaines communal et familial en offrant une versión restreinte et décontextualisé des habiletés lettrées. Dans l'ensemble, l'étude montre que les valeurs et significations associées à la littéracie sont étroitement en rapport avec d'autres facteurs : politiques, sociaux et culturels, qui permettent comprendre les usages et pratiques identifiés et mettre en question les formes actuelles de son enseignement formel..

Mots-clefs:Littératie; écriture; lecture;formel; Amazonie

eferências

AMES, Patricia. Para ser iguales, para ser distintos. Educación, escritura y poder en el Perú. Lima: Instituto de Estudios Peruanos, 2002.

ANDERSON, Jeanine. Yauyos: estudio sobre valores y metas de vida. Ministerio de Educación, Lima, 2001.

ANSIÓN, Juan. La escuela en la comunidad campesina. Proyecto escuela, ecología y comunidad campesina, FAO-Suiza. Ministerio de Agricultura. Lima, 1989.

BARTON, David; HAMILTON, Mary. Local literacies. London: Routledge, 1998.

BARTON, David. Literacy: an introduction to the ecology of written language. Oxford: Blackwell, 1994.

BLOCH, Maurice. The uses of schooling and literacy in a Zafimaniry village. In: STREET, Brian. Cross-cultural approaches to literacy. Cambridge: Cambridge University Press, 1993.

CLASSEN, Constance. Literacy as anticulture: the Andean experience of the written world. History of religion, v. 30, n. 4, p. 404-421, 1991.

DEGREGORI, Carlos Iván. Educación y Mundo Andino. En: POZZI-ESCOTT, Inés; ZÚÑIGA, Madeleine; LÓPEZ, Luis Enrique (Ed.). Educación Bilingüe Intercultural. Reflexiones y desafíos. FOMCIENCIAS, 1991.

DE LA PIEDRA, María Teresa Berta. Literacy practices among Quechuaspeakers: The case study of a rural community in the Peruvian Andes. Dissertation, PhD., May, University of Texas at Austin, 2003.

GODENZZI, Juan Carlos; FLORES, Elizabeth; RAMIREZ, Eliana. Quiero tomar 
la palabra: Comunicación e integración de las niñas en la escuela, la familia y en la comunidad. Ponencia presenteda a la II Conferencia Nacional de Educación de las niñas rurales, 28-29 de Setiembre, Lima, 2000.

GOW, Peter. Of mixed blood: Kinship and history in Peruvian Amazonia. Oxford: Clarendon Press, 1991.

HEATH, Shirley Brice. Ways with words: language, life and work in communities and classrooms. Cambridge: Cambridge University Press, 1983.

IVANIČ, Roz; MOSS, Judith. Bringing community writing practices into education. In: BARTON, David; IVANIČ, Roz (Ed.). Writing in the community. Sage: London, 1991.

LUND, Sara. Bequeathing the quest. Processing personal identification papers in bureaucratic spaces (Cuzco, Peru). Journal of social anthropology, v. 9, n. 1, 2001.

LUND, Sara. On the margin. In: HOWARD-MALVERDE, Rosaleen. Creating Context in andean cultures. Oxford: Oxford University Press, 1997.

MONTOYA, Rodrigo. Por una educación bilingüe en el Perú. Lima: CEPES Mosca Azul Ed., 1990.

NUGENT, Guillermo. EI poder delgado. Lima: Fundación Friedrich Ebert, 1996.

ROBINSON-PANT, Anna. Women's literacy and health: can an ethnographic researcher find the links? In: STREET, Brian (Ed.). Literacy and development. London and New York: Routledge, 2000.

SALOMON, Frank. Academia en las Alturas: reflexiones sobre vida intelectual vernacular, etnografía y educación en la sierra de Lima. Ponencia presentada a la Jornada Nacional de Actualización Docente organizada por IEP-Promperu, Chosica, Julio, 2000.

SALOMON, Frank. Los quipus y libros de Tupicocha de hoy: un informe preliminar. En: VARÓN, R.; FLORES, J. (Ed.). Arqueología, antropología e historia en los Andes. Homenaje a María Rostorowski. Lima: IEP, 1997.

STREET, Brian. Literacy in theory and practice. Cambridge: Cambridge University Press, 1984.

STREET, Brian. Cross-cultural approaches to literacy. Cambridge: Cambridge University Press, 1993.

STREET, Brian. Social Literacies: Critical Approaches to literacy in Ethnography and development. New York: Longman, 1995. 
STREET, Brian. Literacy events and literacy practices: Theory and practice in new literacy studies. En: JONES, Martin; JONES, K. (Ed.). Multilingual literacies: reading and writing different worlds. Amsterdam/Philadelphia: John Benjamins Publishing Company, 2000.

TOVAR, Teresa. Pídele el cuaderno a una alumna aplicada. La niña en la escuela mixta. In: OLIART, P. (Ed.). ¿Todos igualitos? Genero y educación. Lima: PUCP, 1996.

UCCELLI, Francesca. Democracia en el sur andino: posibilidades y esfuerzos de las familias campesinas para educar a sus hijos. En: TANAKA, Martin (Comp.). El poder visto desde abajo. Lima: Instituto de Estudios Peruanos, 1999.

ZAVALA, Virginia. (Des)encuentros con la escritura: escuela y comunidad en los andes peruanos. Lima: Red para el desarrollo de las Ciencias sociales, 2002. 